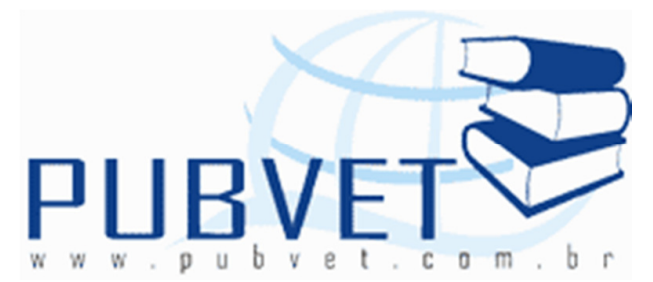

PUBVET, Publicações em Medicina Veterinária e Zootecnia.

\title{
Características morfofisiológicas do gênero Brachiaria
}

Wanderson José Rodrigues de Castro ${ }^{1}$, Claudio Jonasson Mousquer ${ }^{1}$, Michele Carolina Rodrigues de Castro ${ }^{2}$, Vitor Tavares Oliveira Borges ${ }^{1}$, Anderson de Moura Zanine ${ }^{3}$, Ângela Aparecida da Fonseca ${ }^{1}$, Leandro Munhoz Socreppa ${ }^{1}$, Verônica Bandeira Ferreira ${ }^{1}$

${ }^{1}$ Mestrandos em Ciência Animal da Universidade Federal de Mato Grosso, Cuiabá-MT, Brasil

${ }^{2}$ Bióloga, Universidade Federal de Mato Grosso, campus de Rondonópolis-MT

${ }^{3}$ Universidade Federal de Mato Grosso, rua Ponta Pora, bairro Jardim Mato Grosso, UFMT, campus de Rondonópolis-MT, Brasil

\section{Resumo}

O conhecimento das características morfofisiológicas das gramíneas é de suma importância para que as estratégias de manejo sejam aplicadas de forma que venha a favorecer o manejo do pasto, haja vista que em mais de $90 \%$ do rebanho bovino brasileiro é criado exclusivamente nos mesmo. Analisando as situações das nossas áreas de pastagens podemos concluir que mais de $50 \%$ estão em algum processo de degradação, isso se dá por falta de informação de como manejar corretamente nossos pastos e não buscar uma gramínea que venha solucionar os problemas. Sendo assim esta revisão abordara os mecanismos de crescimento da planta para que se possa ter um entendimento maior sobre as mesmas.

Palavras-chave: crescimento; manejo; morfogênese 
CASTRO, W.J.R. et al. Características morfofisiológicas do gênero Brachiaria. PUBVET, Londrina, V. 8, N. 15, Ed. 264, Art. 1757, Agosto, 2014.

\title{
Morphological and physiological characteristics of the genus Brachiaria
}

\begin{abstract}
Knowledge of the morphological and physiological characteristics of the grasses is of utmost importance for management strategies are applied that promotes the sward, given that over $90 \%$ of the Brazilian cattle herd is created exclusively in it. Analyzing the situations of our pastures we can conclude that more than $50 \%$ are in some degradation process, this happens due to lack of information on how to properly manage our pastures and not seek a grass that will solve the problems. So this review approached the mechanisms of plant growth so that we can have a better understanding about them.
\end{abstract}

Keywords: growth; management; morphogenesis

\section{INTRODUÇÃO}

As pastagens brasileiras representam a principal e mais barata fonte de alimento para os ruminantes, principalmente quando se maneja de forma a respeitar os limites ecofisiológicos do pasto através do correto balanço nutricional, monitoramento da taxa de lotação e demais tratos culturais Zanine (2005). Desde o início da exploração agropecuária, se busca pastos que melhor se adaptem as condições dos solos e do clima do nosso país, e até mesmo às suas diversas regiões. Com o passar dos anos houve a constatação de que as espécies do gênero Brachiaria são as que melhor se ajustam a essas condições, mas que mesmo bem adaptadas é necessário que o manejo do pastejo seja realizado de forma a garantir a persistência da espécie Nantes (2009).

O Brasil possuiu cerca de 180 milhões de área de pastagens sendo que deste montante $80 \%$ são do gênero Brachiaria e Panicum; de acordo com Valle et al. (2003), essas duas gramíneas respondem por aproximadamente $85 \%$ das sementes comercializadas para implantação, recuperação ou renovação de pastagens. As Brachiarias são conhecidas pela sua rusticidade em se adaptar 
CASTRO, W.J.R. et al. Características morfofisiológicas do gênero Brachiaria. PUBVET, Londrina, V. 8, N. 15, Ed. 264, Art. 1757, Agosto, 2014.

aos diversos tipos de solos brasileiros, e por possui alta produção de matéria seca e um bom valor nutricional.

Nos últimos anos vem crescendo o número de lançamentos de novas cultivares do gênero Brachiaria de acordo com Martuscello et al. (2006) o lançamento de novos cultivares de gramíneas forrageiras resulta de uma demanda por plantas mais competitivas, menos exigentes em fertilidade do solo, com menor sazonalidade de produção e mais resistentes a pragas e doenças, entre outros fatores.

O conhecimento mais detalhado dos aspectos relativos à fisiologia, morfologia e anatomia das plantas forrageiras é importante toda a vez que se objetiva buscar opções forrageiras melhor adaptadas à produção animal em pastagens em ambientes mais desafiadores, como forma de criar e explorar alternativas de estratégias de manejo que visem à otimização do desempenho da planta Volenec \& Nelson, (1995).

Entre os fatores que definem o valor nutritivo de uma planta forrageira, o consumo voluntário, a palatabilidade, a composição química (energia, proteína, minerais), a digestibilidade e a eficiência de utilização dos nutrientes pelo animal são os mais importantes Costa et al. (2004). No estabelecimento de uma espécie forrageira, a distribuição estacional de sua produção é um parâmetro de grande relevância, já que a baixa disponibilidade e qualidade da forragem, principalmente no período seco, é um dos fatores que mais limita a produtividade dos rebanhos, na média geral a produção de uma gramínea no período seco do ano fica limitado em torno de $20 \%$ enquanto que $80 \%$ e distribuído no período chuvoso, isso se deve a diversos fatores ambientais.

Atualmente, em estudos de estratégias de manejo do pastejo com gramíneas tropicais, tem-se contemplado a interface solo-planta por meio de avaliações morfológicas, fisiológicas e ecológicas das plantas forrageiras. Em adição, tem-se estudado a interface planta-animal, visando à criação de estruturas de pastos adequadas para a planta e para o animal. A partir desse conhecimento, tem sido possível fazer recomendações de manejo mais eficientes. Dessa forma, a morfogênese e a estrutura do pasto, associados à 
CASTRO, W.J.R. et al. Características morfofisiológicas do gênero Brachiaria. PUBVET, Londrina, V. 8, N. 15, Ed. 264, Art. 1757, Agosto, 2014.

mensuração das respostas dos animais no ambiente pastoril, têm sido fundamentais para a compreensão dos efeitos de ações de manejo do pastejo nos processos intrínsecos ao ecossistema da pastagem Santos et al. (2011).

Para estabelecer um manejo adequado do pasto é necessário conhecer e compreender o processo de transformação deste em produção de folhas e, sobretudo, entender e controlar os processos de crescimento e de desenvolvimento que resultam na produção da forragem a ser consumida. Portanto, quando se entende a dinâmica de crescimento e desenvolvimento das plantas em uma pastagem e suas respostas morfofisiológicas, torna-se mais fácil adequar o manejo do pasto visando à sustentabilidade do sistema de produção com alta produtividade, respeitando os limites ecofisiológicos das plantas forrageiras de modo que se obtenha máxima otimização do sistema Nascimento Júnior \& Adese (2004). Sendo assim, esta revisão abordará as características morfofisiológicas e valor nutritivo do gênero Brachiaria sobre pastejo ou corte.

\section{CARACTERÍSTICAS MORFOGÊNICAS}

Lemaire \& Chapman (1996) citado por Alves et al. (2008) afirmaram que o papel principal da morfogênese está ligado à dinâmica de geração e expansão de órgãos vegetais no tempo e no espaço, caracterizando o rendimento de massa seca da parte aérea. Para um pasto em estádio vegetativo, a morfogênese pode ser descrita por três características principais: taxa de aparecimento de folhas (TApF), taxa de alongamento de folhas (TAF) e duração de vida da folha (DVF).

Da Silva \& Nascimento Jr. (2006) diz que o conhecimento da ecofisiologia é necessário para o desenvolvimento de práticas de manejo consistentes com a capacidade produtiva das plantas forrageiras em um dado ambiente. Ainda o mesmo autor fala que, a compreensão dos efeitos do pastejo sobre a planta requer conhecimento e análise das alterações morfofisiológicas, na biomassa radicular e na distribuição vertical das raízes. Esses efeitos são consequências da intensidade e frequência de desfolhação, do tempo de rebrotação (no caso 
CASTRO, W.J.R. et al. Características morfofisiológicas do gênero Brachiaria. PUBVET, Londrina, V. 8, N. 15, Ed. 264, Art. 1757, Agosto, 2014.

de pastejo rotacionado) e da interação entre desfolhação e fatores ambientais, ou seja, disponibilidade hídrica e de nutrientes, intensidade luminosa e estádio fenológico das plantas.

Casa Grande et al. (2010) avaliou as características estruturais e morfogênicas do dossel de Brachiaria brizantha, cv. marandu, manejado em quatro ofertas de forragem 4, 7, 10 e 13\% do PV, em regime de desfolha intermitente, ao longo da estação chuvosa. O autor constatou que a taxa de alongamento da folha (TAF) não foi afetada pela oferta de forragem $(P>0,05)$, entretanto o autor constatou acréscimo nesta variável nas maiores alturas de pastejo (Tabela 01). A média obtida foi de 1,57 cm/graus-dia/perfilho, ficando abaixo da observada por Difante et al. (2011) que obteve $1,74 \mathrm{~cm} /$ perfilho/dia trabalhando com capim marandu entre duas alturas $(15$ e $30 \mathrm{~cm}$ ) e três intervalos de corte. O autor constatou que esta variável aumentou à medida que os ciclos de pastejo foram se sucedendo e atingiu o maior valor no terceiro ciclo ( $23 \mathrm{~mm} /$ perfilho/dia e 2,10 mm/graus/dias/perfilho); no último ciclo foi constatada redução no alongamento de folhas, indicando que as condições ambientais foram inadequadas, assim como no segundo ciclo.

Santos et al. (2011) avaliando o capim-braquiária sob lotação contínua com alturas de 25 e $15 \mathrm{~cm}$ de altura média durante o inverno, com aumento para $25 \mathrm{~cm}$ a partir do início da primavera, observou que a taxa de alongamento foliar (TAF), assim como a taxa de alongamento de pseudocolmo (TAC), foi influenciada apenas pela estação do ano (Tabela 2 ). 0 valor médio de $\operatorname{TAF}(1,02 \mathrm{~cm} /$ perfilho dia) foi cerca de 5 vezes superior ao valor médio de $\operatorname{TAC}(0,19 \mathrm{~cm} /$ perfilho.dia), o que indica grande participação relativa da lâmina foliar e baixa contribuição do pseudocolmo no crescimento do perfilho do capim-braquiária. 
CASTRO, W.J.R. et al. Características morfofisiológicas do gênero Brachiaria. PUBVET, Londrina, V. 8, N. 15, Ed. 264, Art. 1757, Agosto, 2014.

Tabela 1 - Características morfogênicas e estruturais de perfilhos de capimmarandu sob pastejo intermitente em quatro ciclos de pastejo.

\begin{tabular}{|c|c|c|c|c|}
\hline & \multicolumn{4}{|c|}{ Ciclo de Pastejo } \\
\hline & 1 & 2 & 3 & 4 \\
\hline Altura $(\mathrm{cm})$ & $29,3 b$ & $23,5 c$ & $33,8 a$ & $33,2 a$ \\
\hline $\begin{array}{l}\text { Taxa de alongamento de folhas } \\
\text { (mm/dia/perfilho) } \\
\text { Taxa de alongamento de colmos }\end{array}$ & $15,3 \mathrm{bc}$ & $18,1 \mathrm{~b}$ & $22,9 a$ & $13,7 \mathrm{c}$ \\
\hline & $0,6 d$ & $2,9 a$ & $2,0 b$ & $1,3 c$ \\
\hline (folha/dia/perfilho) & $0,08 b$ & $0,11 a$ & $0,12 a$ & $0,08 b$ \\
\hline Filocrono (dias/folhas/perfilho) & $12,8 \mathrm{a}$ & $9,4 b$ & $9,0 \mathrm{~b}$ & $13,6 a$ \\
\hline Duração da vida das folhas (dias/folha) & $47,2 a b$ & $42,3 b$ & $36,8 c$ & $48,6 a$ \\
\hline Número de folhas vivas (folhas/perfilho) & $3,7 \mathrm{c}$ & $4,5 a$ & $4,1 b$ & $3,6 c$ \\
\hline Comprimento final da folha $(\mathrm{mm})$ & $198,6 b c$ & $186,2 \mathrm{c}$ & $223,5 a$ & $212,8 a b$ \\
\hline $\begin{array}{l}\text { Densidade de perfilhos, vegetativos } \\
\text { (perfilhos } / \mathrm{m}^{2} \text { ) }\end{array}$ & $0 c$ & $47,6 b c$ & $193,8 a$ & $81,8 b$ \\
\hline Densidade de perfilhos (perfilhos $/ \mathrm{m}^{2}$ ) & $918 c$ & $1671 a$ & $1742 a$ & $1292 b$ \\
\hline
\end{tabular}

Lara \& Pedreira (2011) avaliando as características morfogênicas e estruturais de cinco cultivares de Brachiaria, com alturas de corte de 15 e 7,5 $\mathrm{cm}$ obteve maior taxa de alongamento de folha à altura de $7,5 \mathrm{~cm}$, a TAF foi de $1,28 \mathrm{~cm}$ por perfilho por dia, enquanto à altura de $15 \mathrm{~cm}$ a TAF foi de 1,09 $\mathrm{cm}$ por perfilho por dia, aproximadamente $15 \%$ menor nessa altura. Segundo Davies (1974) citado por Lara e Pedreira (2011), a TAF é pouco afetada pela desfolhação, e a redução na taxa de alongamento de novas folhas seria afetada em 15 a 20\%, quando todas as folhas do perfilho são removidas. Sendo assim a redução de $50 \%$ na altura de corte, removeu grande quantidade de folhas e afetou a TAF.

Paula Neto et al. (2013) avaliando o capim mulato II sob quatro alturas ( 20, 30, 40 e $50 \mathrm{~cm}$ ) observou que a elevação da altura do dossel forrageiro incrementou positivamente a taxa de alongamento de colmo estimando-se valores médios de 0,17 e 0,49 mm/perfilho para as alturas de 20 e $50 \mathrm{~cm}$ respectivamente. Entretanto a taxa de alongamento foliar (TAF) não foi 
CASTRO, W.J.R. et al. Características morfofisiológicas do gênero Brachiaria. PUBVET, Londrina, V. 8, N. 15, Ed. 264, Art. 1757, Agosto, 2014.

modificada com as estratégias de manejo, com média de 15,15 mm/perfilho dia. O autor também ressalta que essa variável é pouco afetada pelas intensidades de desfolhação.

Tabela 2 - Taxa de alongamento foliar e taxa de alongamento de pseudocolmo em pastos de capim-braquiária manejado sob lotação contínua e com altura fixa ou variável durante as estações do ano.

\begin{tabular}{|c|c|c|c|c|}
\hline \multirow{2}{*}{$\begin{array}{l}\text { Altura do pasto } \\
\text { (cm) }\end{array}$} & \multicolumn{3}{|c|}{ Estação do ano } & \multirow[t]{2}{*}{ Média } \\
\hline & Inverno & Primavera & Verão & \\
\hline \multicolumn{5}{|c|}{ Taxa de alongamento foliar (cm/perfilho/dia) } \\
\hline 25 & 0,095 & 1,350 & 1,609 & $1,018 a$ \\
\hline $15-25$ & 0,124 & 1,521 & 1,409 & $1,018 a$ \\
\hline média & $0,110 b$ & $1,435 a$ & $1,509 a$ & \\
\hline \multicolumn{5}{|c|}{ Taxa de alongamento de pseudocolmo (cm/perfilho/dia) } \\
\hline 25 & 0,011 & 0,241 & 0,300 & $0,184 a$ \\
\hline $15-25$ & 0,005 & 0,228 & 0,352 & $0,195 \mathrm{a}$ \\
\hline Média & $0,008 c$ & $0,235 b$ & $0,326 a$ & \\
\hline
\end{tabular}

Médias seguidas de mesma letra minúscula na linha e maiúscula na coluna não diferem $(P>0,10)$ entre si. Fonte: santos et al. 2011

Casa Grande et al. (2010) constatou que a maior taxa de aparecimento de folha $(0,11$ e 0,12 folha/dia/perfilho ou 0,009 e 0,011 folha/graus dias/ perfilho) foi observado no segundo e terceiro ciclos de pastejo (Tabela 1), enquanto os menores ocorreram no primeiro e último ciclos $(0,08$ folha/dia/perfilho ou 0,007 e 0,006 folha/graus-dias/perfilho, respectivamente), estes dados diferenciaram de santos et al. (2011) (Tabela 3), o autor observou que as estratégias de manejo do pastejo influenciaram de forma diferenciada a taxa de aparecimento foliar (TApF) do capim-braquiária ao longo das estações do ano, o que resultou na interação $(P<0,10)$ entre esses fatores (Tabela 3). Foi constado que durante 0 inverno, o pasto rebaixado para $15 \mathrm{~cm}$ de altura média apresentou maior $(P<0,10)$ TApF se comparado ao pasto com altura fixa de $25 \mathrm{~cm}$. O autor explica que esse fator esta ligado ao tamanho dos perfilhos, já que as folhas teriam um "caminho 
CASTRO, W.J.R. et al. Características morfofisiológicas do gênero Brachiaria. PUBVET, Londrina, V. 8, N. 15, Ed. 264, Art. 1757, Agosto, 2014.

menor" para percorrer até se expandir. Segundo o autor a análise dos dados de filocrono permite constatar que seu padrão de resposta foi contrário ao observado para a TApF (Tabela 3), o que era esperado, uma vez que o filocrono corresponde ao inverso da TApF.

Tabela 3 - Taxa de aparecimento foliar e filocrono em pastos de capimbraquiária manejado sob lotação contínua e com altura fixa ou variável durante as estações do ano.

\begin{tabular}{|c|c|c|c|c|}
\hline \multirow{2}{*}{$\begin{array}{l}\text { Altura do pasto } \\
\qquad(\mathrm{cm})\end{array}$} & \multicolumn{3}{|c|}{ Estação do ano } & \multirow[t]{2}{*}{ Média } \\
\hline & Inverno & Primavera & Verão & \\
\hline \multicolumn{5}{|c|}{ Taxa de aparecimento foliar (folha/perfilho/dia) } \\
\hline 25 & $0,01 b B$ & $0,10 \mathrm{aA}$ & $0,11 \mathrm{aA}$ & 0,08 \\
\hline $15-25$ & $0,02 \mathrm{bA}$ & $0,11 a A$ & $0,12 \mathrm{aA}$ & 0,08 \\
\hline Média & 0,02 & 0,11 & 0,12 & \\
\hline \multicolumn{5}{|c|}{ Filocrono (dia/folha) } \\
\hline 25 & $98,4 a A$ & $10,5 \mathrm{bA}$ & $8,9 \mathrm{ba}$ & 39,0 \\
\hline $15-25$ & $53,0 a B$ & $9,2 \mathrm{ba}$ & $8,0 \mathrm{ba}$ & 23,4 \\
\hline Média & 75,7 & 9,8 & 8,5 & \\
\hline
\end{tabular}

Médias seguidas de mesma letra minúscula na linha e maiúscula na coluna não diferem $(P>0,10)$ entre si. Fonte: santos et al. 2011

Casa Grande et al. (2010) observou que a duração de vida da folha respondeu apenas à variação dos ciclos de pastejo $(P<0,0001)$, com valores que variaram de 36,8 a 48,6 dias, o menor delas ocorreu no terceiro ciclo (Tabela 1). Esses valores estão próximos daqueles citados por Corsi et al. (1994) para Brachiaria brizantha, que variaram de 37 a 47 dias.

Já Santos et al. (2011) não constatou efeito de interação $(P>0,10)$ entre estratégia de manejo do pastejo e estação do ano. Contudo, seus valores foram maiores $(P<0,10)$ no inverno e no pasto manejado sob altura fixa durante todo o período experimental (Tabela 4). Segundo o autor a maior DVF verificada no pasto de capim-braquiária manejado com altura média fixa e igual a $25 \mathrm{~cm}$ pode ser atribuída ao seu maior filocrono (Tabela 3). Estes resultados corroboram com Lara e Pedreira (2011) que obteve maior DVF na altura de maior manejo que foi de $15 \mathrm{~cm}$, segundo o mesmo autor, essa 
CASTRO, W.J.R. et al. Características morfofisiológicas do gênero Brachiaria. PUBVET, Londrina, V. 8, N. 15, Ed. 264, Art. 1757, Agosto, 2014.

redução na longevidade é resultado da maior dinâmica de renovação de tecidos e perfilhos, nessas condições.

Tabela 4 - Duração de vida da folha e taxa de senescência foliar em pastos de capim-braquiária manejado sob lotação contínua e com altura fixa ou variável durante as estações do ano.

\begin{tabular}{|c|c|c|c|c|}
\hline \multirow{2}{*}{$\begin{array}{l}\text { Altura do pasto } \\
\text { (cm) }\end{array}$} & \multicolumn{3}{|c|}{ Estação do ano } & \multirow[t]{2}{*}{ Média } \\
\hline & Inverno & Primavera & Verão & \\
\hline \multicolumn{5}{|c|}{ Duração de vida da folha (dia) } \\
\hline 25 & 147,9 & 39,2 & 38,3 & $75,1 \mathrm{~A}$ \\
\hline $15-25$ & 129,7 & 33,2 & 34,8 & $65,9 B$ \\
\hline Média & $138,8 a$ & $36,2 b$ & $36,5 b$ & \\
\hline \multicolumn{5}{|c|}{ Taxa de senescência (cm/perfilho/dia) } \\
\hline 25 & $0,34 \mathrm{bA}$ & $0,51 \mathrm{aA}$ & $0,25 b A$ & 0,37 \\
\hline $15-25$ & $0,18 \mathrm{Bb}$ & $0,29 a B$ & $0,19 a b A$ & 0,22 \\
\hline Média & 0,26 & 0,40 & 0,22 & \\
\hline
\end{tabular}

\section{CARACTERÍSTICAS ESTRUTURAIS}

Marcelino et al. (2006) destaca que, as principais características estruturais das pastagens são determinadas pela combinação das variáveis morfogênicas básicas que são: densidade populacional de perfilhos, tamanho da folha e número de folhas vivas por perfilho. A taxa de aparecimento de folhas exerce papel central na morfogênese por causa da sua influência direta sobre cada um dos três componentes da estrutura da pastagem.

O conjunto de características estruturais determina o índice de área foliar dos pastos (IAF) que, por sua vez, define ou modifica o ambiente luminoso no interior do dossel forrageiro por promover alterações na qualidade $e$ quantidade de luz disponível. Essas mudanças de ambiente interno resultam em modificação da expressão morfogênica das plantas durante o ciclo de rebrotação, interferindo na quantidade, composição morfológica e valor 
CASTRO, W.J.R. et al. Características morfofisiológicas do gênero Brachiaria. PUBVET, Londrina, V. 8, N. 15, Ed. 264, Art. 1757, Agosto, 2014.

nutritivo da forragem produzida Da Silva et al. 2009 citado por Barbero (2011).

De acordo com Fagundes (2006) o sucesso na utilização de pastagens não depende apenas da disponibilidade de nutrientes ou da escolha da espécie forrageira, mas também da compreensão dos mecanismos morfofisiológicos e de sua interação com o ambiente e do manejo, fundamental para o crescimento da forrageira e a manutenção da capacidade de suporte da pastagem. Ainda o mesmo autor cita que a densidade populacional de perfilhos e o índice da área foliar são características de grande destaque, pois interferem na produção de forragem e no consumo de matéria seca pelos animais.

Os perfilhos são as unidades básicas para o desenvolvimento de uma gramínea, em uma mesma planta podem existir vários perfilhos de diferentes idades e, por conseguinte, com distintas características morfológicas. Essa diversidade de perfilhos em gramíneas também confere alta heterogeneidade de perfilhos no pasto. De fato, a estrutura complexa e heterogênea do pasto pode ser atribuída à sua grande diversidade de perfilhos no tocante à idade, estádio de desenvolvimento, origem de crescimento, nível de desfolhação, dentre outros (Santos et al., 2010).

Casa Grande et al. (2010) avaliando as características morfogênicas e estruturais de perfilhos de capim-marandu, observou que no primeiro ciclo de pastejo, foi observada a mais baixa densidade de perfilhos totais $\left(918 \mathrm{p} / \mathrm{m}^{2}\right)$ durante todo período experimental. No segundo e terceiro ciclos de pastejo, constatou-se aumento significativo dessa variável (1671 e 1742 p/m²), fator que o autor atribui ao efeito favorável da aplicação de nitrogênio no início do segundo ciclo sobre o perfilhamento.

Lara \& Pedreira (2011) avaliando as características morfogênicas e estruturais de cinco cultivares de Brachiaria, com alturas de corte de 15 e 7,5 $\mathrm{cm}$ constatou que a densidade populacional de perfilhos sofreu efeito da estação $(P=0,0268)$ e da interação entre a altura de corte $x$ genótipo $(P=0,0027$; Tabela 5). A DDP foi maior na sub parcelas cortadas a $7,5 \mathrm{~cm}$ de 
CASTRO, W.J.R. et al. Características morfofisiológicas do gênero Brachiaria. PUBVET, Londrina, V. 8, N. 15, Ed. 264, Art. 1757, Agosto, 2014.

altura, apenas o capim Arapoty a DDP foi maior na altura de $15 \mathrm{~cm}$. A maior DDP foi encontrada no capim Capiporã 1620 perfilhos $\mathrm{m}^{2}$ quando este foi colhido a $7,5 \mathrm{~cm}$. $O$ autor relata que este fator está ligado à severidade da desfolha, já que com a menor altura de manejo $(7,5 \mathrm{~cm})$ ocorreu maior introdução de luz no dossel, estimulando assim as gemas basais.

Tabela 5. Densidade populacional de perfilhos (perfilhos $\mathrm{m}^{2}$ ) de cinco genótipos de Brachiaria spp. sob duas alturas de corte.

\begin{tabular}{ccccccc}
\hline Estação & \multicolumn{5}{c}{ Genótipo } \\
\hline & Arapoty & Basilisk & Capiporã & Marandu & Xaraés & Média \\
\cline { 2 - 6 } & & & \multicolumn{5}{c}{ Perfilhos m² } \\
\hline $15 \mathrm{~cm}$ & $1334 \mathrm{Aa}$ & $962 \mathrm{BCb}$ & $1480 \mathrm{Ab}$ & $1023 \mathrm{Bb}$ & $795 \mathrm{Cb}$ & 1123 \\
$7,5 \mathrm{~cm}$ & $1195 \mathrm{Bb}$ & $1126 \mathrm{Ba}$ & $1620 \mathrm{Aa}$ & $1190 \mathrm{Ba}$ & $1005 \mathrm{Ba}$ & 1227 \\
Média & 1264 & 1044 & 1560 & 1107 & 900 &
\end{tabular}

Letras minúsculas na coluna comparam entre alturas de corte para o mesmo genótipo $(P<0,05)$. Letras maiúsculas na linha comparam médias entre genótipos na mesma altura de corte $(P<0,05)$. Fonte: Lara 2011

Casa Grande et al. (2010) observou que o número de folhas vivas variou apenas entre os ciclos de pastejo $(P<0,0001)$, uma vez que não foi constatado efeito significativo da oferta de forragem nem da interação entre ciclo de pastejo e oferta de forragem $(P>0,05)$. Os valores variaram de 3,6 a 4,5 folhas/perfilho e, no segundo e terceiro ciclos, os perfilhos apresentaram maiores números de folhas vivas, 4,5 e 4,1 folhas/perfilho, respectivamente (Tabela 1). O número de folhas vivas é relativamente constante para cada genótipo, ou seja, quando uma folha senesce, surge uma nova folha no mesmo perfilho (Hodgson, 1990).

Estes resultados diferiram de Lara \& Pedreira (2011) que obteve média de 5,4 para a cultivar marandu (Tabela 6). O autor verificou que o NFV sofreu efeito da interação entre altura de corte $x$ genótipo. Apenas as cultivares Basilisk e Marandu tiveram NFV diferentes entre as alturas de corte, sendo que, nas subparcelas cortadas a $15 \mathrm{~cm}$ de altura, elas tinham menos folhas vivas por perfilho (Tabela 6). Dessa forma, dosséis cortados mais rentes ao 
CASTRO, W.J.R. et al. Características morfofisiológicas do gênero Brachiaria. PUBVET, Londrina, V. 8, N. 15, Ed. 264, Art. 1757, Agosto, 2014.

solo tiveram maior NFV, em comparação aos dosséis colhidos mais altos. Paula Neto et al. (2013) trabalhando com capim mulato II sob quatro alturas (10, 20 , 30 e $40 \mathrm{~cm}$ ), obteve média de NFV de 5,60 resultados bem próximo ao de Lara \& Pedreira (2011).

Tabela 6. Número de folhas vivas por perfilho de cinco genótipos de Brachiaria spp. sob duas alturas de corte.

\begin{tabular}{ccccccc}
\hline Estação & \multicolumn{5}{c}{ Genótipo } \\
\hline & Arapoty & Basilisk & Capiporã & Marandu & Xaraés & Média \\
\cline { 2 - 7 } & & \multicolumn{5}{c}{ Número de folhas } \\
$7,5 \mathrm{~cm}$ & $5,1 \mathrm{ABa}$ & $4,4 \mathrm{Cb}$ & $4,5 \mathrm{BCa}$ & $5,1 \mathrm{ABb}$ & $5,4 \mathrm{Aa}$ & 4,9 \\
$7,5 \mathrm{~cm}$ & $5,2 \mathrm{ABCa}$ & $5,1 \mathrm{Bca}$ & $4,8 \mathrm{Ca}$ & $5,7 \mathrm{Aa}$ & $5,4 \mathrm{ABa}$ & 5,3 \\
Média & 5,2 & 4,7 & 4,7 & 5,4 & 5,4 &
\end{tabular}

Letras minúsculas na coluna comparam entre alturas de corte para o mesmo genótipo $(P<0,05)$. Letras maiúsculas na linha comparam médias entre genótipos na mesma altura de corte $(P<0,05)$. Fonte: Lara, (2011).

Em relação ao comprimento final da folha Casa Grande et al. (2010) não observou variação entre as ofertas de forragem $(P>0,05)$, com média geral de $205 \mathrm{~mm}$. Verificou-se, porém, tendência $(P=0,06)$ de aumento linear nesta variável nas maiores ofertas de forragem. A média encontrada para a oferta de $4 \%$ do PV/dia foi de $194 \mathrm{~mm}$, enquanto na maior oferta de forragem o autor constatou média de $210 \mathrm{~mm}$. O comprimento final da folha variou com os ciclos de pastejo $(P<0,0001)$, não sendo observada a interação entre os fatores ( $P>0,05)$ Casa Grande et al. (2010).

Já para Lara \& Pedreira (2011), o comprimento final de folhas expandidas (CFF) sofreu efeito da altura de corte e da interação genótipo x estação. Nas subparcelas cortadas a $15 \mathrm{~cm}$, o CFF obteve média de $18,66 \mathrm{~cm}$, enquanto que nas subparcelas cortadas a 7,5 cm, o CFF foi menor e correspondeu a 11,64 $\mathrm{cm}$ de média. No verão agrostológico, o CFF foi sempre maior para todos os genótipos, em comparação ao do inverno. A cultivar Capiporã destacou-se por ter as folhas expandidas mais longas, tendo superado os $25 \mathrm{~cm}$ de comprimento, no verão (Tabela 7). Neto (2013) também verificou que o 
CASTRO, W.J.R. et al. Características morfofisiológicas do gênero Brachiaria. PUBVET, Londrina, V. 8, N. 15, Ed. 264, Art. 1757, Agosto, 2014.

comprimento final da folha sofreu efeito da altura, obtendo resultado linear positivo à medida que a altura do dossel foi aumentando.

Tabela 7. Comprimento final de folhas expandidas de cinco genótipos de Brachiaria spp. no verão e inverno agrostológico.

\begin{tabular}{ccccccc}
\hline Estação & \multicolumn{5}{c}{ Genótipo } \\
& Arapoty & Basilisk & Capiporã & Marandu & Xaraés & Média \\
\cline { 2 - 7 } & & & \multicolumn{2}{c}{$\mathrm{cm}$} \\
\hline Verão & $20,3 \mathrm{Ba}$ & $18,9 \mathrm{Ba}$ & $25,3 \mathrm{Aa}$ & $12,4 \mathrm{Da}$ & $16,4 \mathrm{Ca}$ & 18,66 \\
Inverno & $11,8 \mathrm{Bb}$ & $11,4 \mathrm{Bb}$ & $15,3 \mathrm{Ab}$ & $9,5 \mathrm{Cb}$ & $10,2 \mathrm{BCb}$ & 11,64 \\
Média & 16,0 & 15,1 & 20,3 & 10,9 & 13,3 & \\
& & & & & &
\end{tabular}

Letras minúsculas na coluna comparam médias entre estações para o mesmo genótipo $(P<0,05)$. Letras maiúsculas na linha comparam médias entre genótipos na mesma estação $(P<0,05)$. Fonte: Lara , (2011).

\section{CONCLUSÃO}

O conhecimento das respostas morfofisiológicas das plantas forrageiras tropicais é de suma importância para o entendimento e planejamento de estratégias e práticas de manejo do pastejo, uma vez que definirão os limites tanto da planta como do animal, sendo assim, cabe aos técnicos impor técnicas de manejo adequadas para a otimização do sistema como um todo.

\section{REFERÊNCIAS}

ALVES, J.S.; PIRES, V.J.A.; MATSUMOTO, N.S.; FIGUEIREDO, P.M.; RIBEIRO, S.G. Características morfológicas e estruturais da brachiaria decumbens stapf. submetida a diferentes doses de nitrogênio e volumes de água. Acta Veterinaria Brasilica, v.2, n.1, p.1$10,2008$.

COSTA, N.L; GONÇALVES, C.A.; OLIVEIRA, M.A.S.; OLIVEIRA, J.R.C.; MAGALHÃES, J.A. Resposta de Brachiaria brizantha cv. Marandu à regimes de cortes. Porto Velho: Embrapa Rondônia, 2004. 3p. (Embrapa Rondônia. Comunicado Técnico, 279).

DA SILVA \& NASCIMENTO JR. Ecofisiologia de Plantas Forrageiras. In: PEREIRA, O.G., OBEID, J.A., NASCIMENTO Jr., D. FONSECA, D.M., (Eds.). Simpósio sobre Manejo Estratégico da Pastagem, III, Viçosa, 2006. Anais... Viçosa : UFV, 2006, p.1-42, 430p.

FAGUNDES, J.L.; FONSECA, D.L.; MISTURA, C. et al. Características morfogênicas e estruturais do capim-braquiária em pastagem adubada com nitrogênio avaliadas nas quatro estações do ano. Revista Brasileira de Zootecnia, v.35, n.1, p.21-29, 2006. 
BARBEIRO, L.M. Respostas morfogênicas e caracteristicas estruturais do capim mulato submetido a estratégias de pastejo rotativo. Tese (doutorado). Escola superior de agricultura Luiz de Queiroz. Piracicaba 2011.

MARCELINO, K.R.A.; NASCIMENTO JUNIOR, D.; SILVA, S.C. et al. Características morfogênicas e estruturais e produção de forragem do capim-marandu submetido a intensidades e freqüências de desfolhação. Revista Brasileira de Zootecnia, v.35, n.6, p.2243-2252, 2006.

LARA, M.A.S.; PEDREIRA, C.G.S. Respostas morfogênicas e estruturais de dosséis de espécies de Braquiária à intensidade de desfolhação. Pesquisa Agropecuária Brasileira, Brasília, v.46, n.7, p.760-767, jul. 2011.

MARTUSCELLO A.J. et al. Características morfogênicas e estruturais de capim-massai submetido a adubação nitrogenada e desfolhação. Revista Brasileira de Zootecnia, v.35 n.3, 2006.

NASCIMENTO JÚNIOR D.; ADESE B. 2004. Acúmulo de biomassa na pastagem. In: SIMPÓSIO SOBRE MANEJO ESTRATÉGICO DA PASTAGEM, 2, 2004, Viçosa. Anais... Viçosa: UFV, p.289330.

PAULA NETO, J.J.; ALEXANDRINO, E.; MELO, J.C.; REZENDE, J.M.; SILVA, D.P.; SILVA, A.A.M.; SOUSA JÚNIOR, A.; OLIVEIRA, A.K.R. Respostas morfogênicas e estruturais do capimHD364 sob-regimes de lotação contínua. Anais, XXIII congresso brasileiro de zootecnia. Foz do Iguaçu/PR, 06 a 09 de maio de 2013.

SANTOS, M. E. R; FONSECA, D. M. da; G.V. M.; PIMENTEL, R. M.; SILVA, G. P.; Silva. S. P. da. Caracterização de perfilhos de capim-braquiária em locais com três intensidades de pastejo. Revista Brasileira de Saúde e Produção Animal, v.11, n.4, p. 961-975, 2010.

SANTOS, M. E. R; FONSECA, D. M. da; G.V. M.; PIMENTEL, R. M.; SILVA, G. P.; Silva. S. P. da. Capim-braquiária sob lotação contínua e com altura única ou variável durante as estações do ano: morfogênese e dinâmica de tecidos. Revista Brasileira de Zootecnia, v.40, n.11, p.2323-2331, 2011.

VOLENEC, J.J.; NELSON, C.J. Forage crop management: Applications of emerging technologies. In: Heath, M. E., Metcalfe, D. S., Barnes, R. F. (Eds.). Forages: The science of grassland agriculture, 3 Ed. Vol. 1. The Iowa State University Press, Iowa, USA, p.3-20. 1995.

ZANINE, A.M. Resposta morfofisiológica em pasto sob pastejo. Colloquium Agrariae, v. 1, n.2, p. 50-59, 2005. 